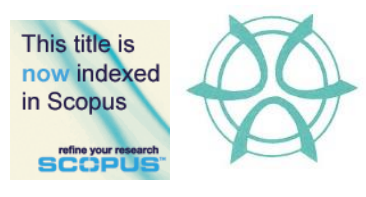

PLANNING MALAYSIA:

Journal of the Malaysian Institute of Planners

VOLUME 15 ISSUE 1 (2017), Page 31 - 44

\title{
FIELD, LIGHT AND FOOD: ADAPTING OF THE TOWN SQUARE AS A LEISURE GATHERING SPACE AT NIGHT
}

\author{
Khalilah Zakariya $^{1}$, Nor Zalina Harun ${ }^{2}$, \& Mazlina Mansor ${ }^{3}$ \\ ${ }^{1,2,3}$ Kulliyyah of Architecture and Environmental Design \\ INTERNATIONAL ISLAMIC UNIVERSITY MALAYSIA
}

\begin{abstract}
A square is an important built open space in cities and towns. In many urban areas throughout the world squares act as essential form of public space, making them a venue where socializing, meeting and event activities take place. Over the years, more squares are emerging as public spaces in Malaysian cities and towns as an alternative to parks. While most people often visit parks in the morning and evening, they still need a public space where they can conduct their leisure activities after working hours and at night. This is particularly relevant for towns and cities located in tropical and humid countries like Malaysia. The rising need to be outdoors in a cooler environment in the evening and at night, as a respite from the daytime heat and work, has attracted people back to the town squares. The sense of openness that a square offers is different from that of a park at night. The attractiveness of a square as a night space relies on how its users relate to the square's physical, social and environmental attributes. Through examining a town square in Malaysia that has transformed into an active public space at night, this article aims to explore the attributes that enabled the square to be adapted into a night space. The findings revealed that there is a strong relationship between the opportunities for various activities and the provision of relevant infrastructure that support the square to serve as a public space for people at night. This is an important tangent in shifting how urban public space in Malaysia might be designed and planned in the future so as to cater for the changing needs of urban dwellers.
\end{abstract}

Keyword: urban square, town square, public space, urban design

Date Received: $30^{\text {th }}$ April 2016

Date of Acceptance: $30^{\text {th }}$ October 2016 
Khalilah Zakariya, Nor Zalina Harun, \& Mazlina Mansor

Field, Light and Food: Adapting of the Town Square as a Leisure Gathering Space at Night

\section{INTRODUCTION}

Square, also referred to as plaza, is an important urban space that has vital roles dated back to the early civilizations until today. Generally, squares function as places for people to gather, whether to socialize or engage in leisure activities (Nur Azlini Abdullah, 2004; Tibbalds, 1992). They are a type of civic places that allows people to socialize and interact with each other in the public (Childs, 2004). Squares with historical and cultural significance often become landmarks for towns and cities (Lynch, 1960, 1981), such as the Tiananmen Square in Beijing, China, the Djemaa El-Fnaa in Marrakech, Morocco and the Trafalgar Square in London, United Kingdom. In Malaysia, the Dataran Merdeka is one of the prominent historic squares that have similarly become an urban and tourism landmark in Kuala Lumpur (Khalilah Zakariya \& Nor Zalina Harun, 2013; Nor Zalina Harun \& Ismail Said, 2008).

The attractiveness of an urban square is generally contributed by its design, location, surrounding context and facilities that can accommodate people's diverse activities. Its activeness is supported by the availability of other active activities, such as the presence of eateries, food stalls and shops. While these factors may help to sustain the life of a square weekly, the square needs to be managed and planned for events throughout the year in order to attract larger crowds from time to time. As written by Whyte (1980), 'what attracts people most, it would appear, is other people'. These supporting spaces and activities influence the activeness of the plaza, and vice versa because essentially, urban spaces operate as a connected system (Cooper-Marcus \& Francis, 1998; Lynch, 1981).

Due to the perceived popularity of squares in major cities, more squares have been designed in other towns and cities in Malaysia. However, not all squares remain active and vibrant as they were initially planned. The roles of squares need to adapt to the process of urbanization and changes in lifestyle of their users. Cooper-Marcus and Francis (1998) suggest that squares in contemporary society are not the same as squares in the older civilizations. Nonetheless, the contextual and functional attributes that make a square successful are still applicable and need to be adaptable to contemporary setting. Consequently, some squares are left underutilized and perceived as a waste of urban open space. This is a critical point where the functions and roles of a square in its very own context need to be well understood. Designing and planning a square is not merely about adopting successful design from elsewhere and hoping that it would function in the same way. Rather, it is vital for us to learn about what makes certain squares active and inactive, and then adapt the lessons to how squares can be designed and managed in the future.

As such, embarking from this position, this article aims to examine factors that contribute to the attractiveness and activeness of a town square through a case study located in Ipoh, Perak in Malaysia. The square, Dataran 
PLANNING MALAYSIA

Journal of the Malaysia Institute of Planners (2017)

Majlis Bandaraya Ipoh (Dataran MBI), acts as a pilot study for the research to explore the physical and functional dimensions that influence the vitality of an urban square as a night public space that builds upon the image of the city. This study is significant in establishing the parameters for the larger body of research on squares and public space in the Malaysian context.

\section{URBAN SQUARE: THEN AND NOW}

Historically, public spaces for people to gather have evolved since the early Islamic and Western cities, which initially derived from religious spaces (Kostof, 1992). As an expansion of this public space, cities extended their streets and built open spaces into square or plaza. For instance in the Islamic city, the maidan (square) can be found to be located in the middle of residential, commercial and mosque areas (Kostof, 1992). The functions of squares back then are different from present days. As an example, the maidan in early Iranian cities are utilized for horse racing sports, polo-field and market area. Early Western cities have also found to have city squares as a public space. Evidence of this can be traced back to the development of Greek cities, where squares functioned as an aesthetic social space for people to interact (Carmona, Heath, Oc, \& Tiesdell, 2003).

In the recent years, the European Square Conference (ESC) reported several issues regarding the role of squares in today's cities (International Making Cities Livable, 2002). Some of the challenges for squares in Europe consist:

a) Uncontrolled commercial and suburban development at the city's periphery;

b) Mass tourism that turns the historic square into a tourist attraction;

c) The square's increasing monofunctional character;

d) Promotion of information technology that attempts to replace social life on the square with virtual agora.

The European Square Conference (ESC) further acknowledged that, "in order (for the square) to function, social and economic life had to be organized through negotiation and consensus, by establishing democratic principles in the equitable use of place". According to the ESC, urban squares and plazas are found to be:

a) A representation of the city's unique identity;

b) A potential "market place";

c) Have potential for "mixed use and diversity";

d) Need "appropriate balance between resident and tourist use of the square";

e) A place for "social learning environment".

The concern over the issue of urban squares in Europe is not much different from that in Asia, although research on Malaysia's urban square and its 
Khalilah Zakariya, Nor Zalina Harun, \& Mazlina Mansor

Field, Light and Food: Adapting of the Town Square as a Leisure Gathering Space at Night

multifaceted roles as a night public space is still very scarce. An example of this can be seen at the Heritage Bazaar in Dataran Pahlawan Megamall in Banda Hilir, Malacca. Dataran Pahlawan is an urban square that has been renovated to be raised above the ground level to provide shops and food courts underneath it. Recent studies on Dataran Pahlawan revealed the square to be less active than before, other than during events and celebrations held occasionally throughout the year. This had led to the decline of income for some of the small business operators.

\section{METHODOLOGY}

This study uses a case study approach in order to examine how an urban square functions as a night space. This case study is part a larger research work that examines other squares in Malaysia. Researchers in the field of built environment often utilize a case study approach to understand and examine conditions and phenomena of spaces (Denscombe, 2007; Francis, 2003; Zeisel, 1984). This approach is adopted for this study to allow the researchers to explore and understand in-depth about the urban square and its users (Yin, 2003; Zaidah Zainal, 2007). Therefore, the pilot study acts as an exploratory case study to guide the preparation of the framework of the larger body of research. This is fundamental in determining the research operations that will be adopted in the next phases.

Two main methods were employed in this study, which are (i) conducting survey questionnaires to visitors, and (ii) conducting observation and site mapping. Survey questionnaires have the advantage to reach a reasonable representative group of people in a short period of time. This data is essential in identifying the types of users, their motivations for coming and their level of experience and satisfaction conducting their activities at the square. The respondents to the survey were people that visited the square during the days of the fieldwork, which covered weekdays and weekends, during the day, evening and at night. This is done to ensure that the collected data will be able to represent the different types of users and their activities at the square. 72 respondents $(\mathrm{N}=72)$ were surveyed during the fieldwork.

Observation and site mapping are methods commonly employed in environment-behaviour research. As a method of data collection, observation does not rely on what people say or think they do, but rather on documenting what they actually do by means of observing (Denscombe, 2007; Zeisel, 1984). The observation is documented using photographs and site mapping diagrams to support the quantitative data gained from the survey questionnaire. Mapping allows the researcher to illustrate the connections between the users, the square and the surrounding context. The observations were conducted systematically using fieldwork form that has been prepared prior to the field work. The observations were conducted in four sections during weekdays and weekend: 
a) Morning (between 8.00 am to 12.00 noon) - when people visit the square on weekdays and weekends

b) Lunch break (between 12.00 noon to $2.00 \mathrm{pm}$ ) - when people pass by the square during their lunch break

c) Late afternoon to evening (between $2.00 \mathrm{pm}$ to $6.00 \mathrm{pm}$ ) - when most people start to have their recreational activities after school, after office hours and on weekend evenings

d) Night (6.00 pm to 12 midnight) - night activities and outdoor eating

The selection of mix methodology that combines quantitative and qualitative data in this study helps to achieve the research aim. The crossexamination between quantitative and qualitative data provides a pragmatic way of justifying and explaining the research findings. According to Yin (2003), the generalization from the findings of case study research contributes to expand our understanding of theories through the identification of patterns or repetitive conditions.

The findings from the data collected at the square from both methods are then cross-examined to extract the key findings that inform how the urban square is used as public space and as domestic tourist attraction.

\section{FINDINGS}

\section{Dataran Majlis Bandaraya Ipoh as a Town Square}

Dataran Majlis Bandaraya Ipoh (Dataran MBI) is located in Greentown, which is part of the new town development in Ipoh (Figure $1 \& 2$ ). The square is located in front of Majlis Bandaraya Ipoh, the local authority of Ipoh. Dataran MBI is selected as the case study because of the presence of active temporary food stalls that operate at night along the square, known as the MBI Terrace. This makes the square popular with locals and visitors to Ipoh. Its nightlife represents an emerging trend of informal activities and recreations conducted at night, particularly on weekends and during public holidays.

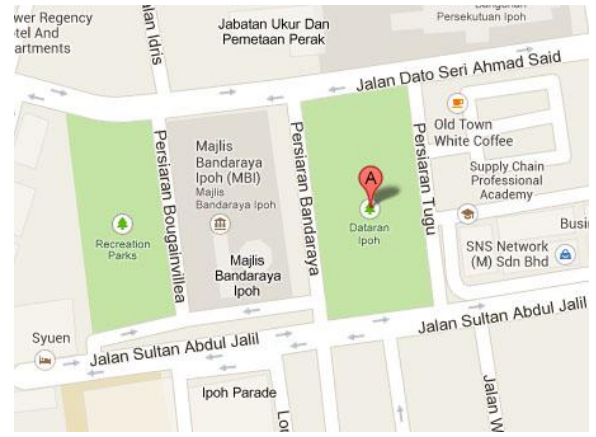

Figure 1 Location Plan of Dataran MBI

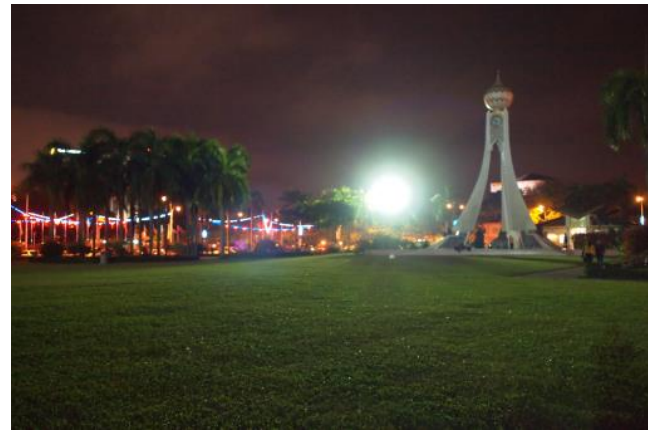

Figure 2 Image of the Square at Night 
Khalilah Zakariya, Nor Zalina Harun, \& Mazlina Mansor

Field, Light and Food: Adapting of the Town Square as a Leisure Gathering Space at Night

Dataran MBI is surrounded by a commercial area and two main roads. The square is designed with an open green field in the centre and paved walkway around it. The focal point of the square is the clock tower, which is located on a raised plaza (Figure 3). In the daytime, people who work and visit the area occupy the parking spaces around the square.

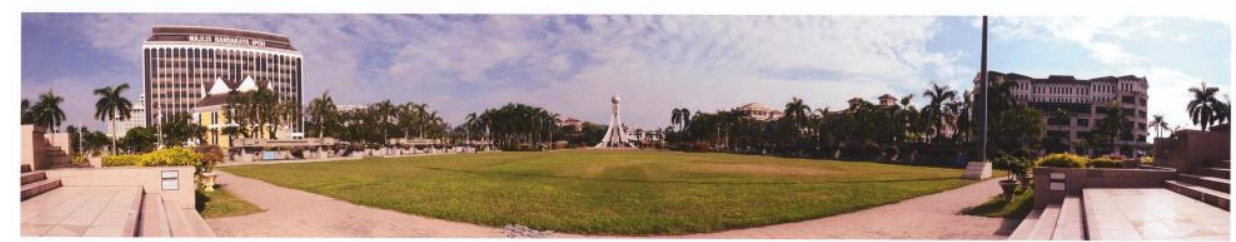

Figure 3 Panoramic View of the Square

\section{Visitor's Profile}

Based on the survey questionnaire, it was found that the majority of the visitors at Dataran MBI were Malay (93.1\%). The majority of the visitors are young adults, aged between 20 and 29 (69.4\%), followed by those aged 30 to 39 $(12.5 \%)$. Children are also present with some of the adults, as they come as a family.

Interestingly, the majority of the visitors came from outside of Ipoh. $20.8 \%$ came from other places in Perak, while $40.3 \%$ came from other states in Malaysia. The number of out of state visitors signifies that domestic tourists also visit Dataran MBI. Most visitors come with other people to the square, where $43.1 \%$ came in a big group, $37.5 \%$ came with their friends or partner, and $19.4 \%$ came with their families. This clearly demonstrates the role of the square as a social space.

\section{Motivations for Visit}

The data presented in Table 1 provides an overview of the visitors' motivations and experiences at Dataran MBI. This includes their main purpose of the visit, frequency of visit and the activities that they do at the square.

Table 1 Main Purpose of Visit to Dataran MBI

\begin{tabular}{ll}
\hline Activities` & Percentage \\
\hline Eating & $31.9 \%$ \\
Recreation & $29.2 \%$ \\
$\begin{array}{l}\text { Others (meeting people, business, attending events, } \\
\text { others) }\end{array}$ & $38.9 \%$ \\
\hline
\end{tabular}

The survey reveals that the main purposes of visiting Dataran MBI are for eating (31.9\%), recreation (29.2\%), meeting friends and relatives, business and attending events. All of these activities are strongly related to the role of the 
PLANNING MALAYSIA

Journal of the Malaysia Institute of Planners (2017)

square as an urban open space in Ipoh. The most popular activities engaged by visitors are eating (22\%) and recreation (21\%). The intensity of these activities compared to other activities is relevant to the types of spaces provided at Dataran MBI. The MBI Terrace food stalls offer the visitors an outdoor eating experience at night. Visitors are also able to get a variety of food at affordable prices. On the other hand, the open green field, the walkways and raised plaza enables visitors to conduct recreational and leisure activities, such as strolling, jogging, and sitting, and as a kick-about area (Figure 5-7).

Table 2 Space Utilization at Dataran MBI

Activities
During the day, the square is least active. The
perimeter of the square is mostly used for parking.
This part of the sidewalk is called MBI Terrace,
where food stall vendors operate at night.
From about 5 pm until midnight, food stall vendors
utilize the sidewalks on one side of the square,
called the MBI Terrace. Many visitors are seen to
visit and dine at the food stalls. All of the vendors
are Malay and most of the customers are also
Malays.
Children and families gather, sit and played on the
raised platform where the clock tower is located.
the mawlid and religious lectures that are open to
crowd to the open green field.


Khalilah Zakariya, Nor Zalina Harun, \& Mazlina Mansor

Field, Light and Food: Adapting of the Town Square as a Leisure Gathering Space at Night

Most of the visitors visit the square at least once a year (23.6\%) or once a month (20.8\%), while there are those that visit the square occasionally or by chance when they happen to be in town (26.4\%) (Table 3). The peak time of the visit at Dataran MBI is at night, from 7 pm until 12 midnight (37.5\%). This is followed by late evening, from $5 \mathrm{pm}$ until $7 \mathrm{pm}(25 \%)$. This finding is closely related to the eating activities at MBI Terrace, where food stall vendors start to operate from about $5 \mathrm{pm}$ until midnight. Interestingly, there are users that occupy the square during the daytime $(22.2 \%)$. This is contributed by the parking facilities and adjacency of the square to the commercial area that operates actively during the day.

Table 3 Frequency and Time of Visit to Dataran MBI

\begin{tabular}{ll}
\hline Activities & Percentage \\
\hline Occasional or by chance & $26.4 \%$ \\
Once a year & $23.6 \%$ \\
Once a month & $20.8 \%$ \\
$7 \mathrm{pm}-12$ midnight & $37.5 \%$ \\
$5 \mathrm{pm}-7 \mathrm{pm}$ & $25 \%$ \\
$9 \mathrm{am}-12$ noon & $22.2 \%$ \\
\hline
\end{tabular}

There are several activities that visitors do at the square. Eating and drinking was found to be the main activities $(M=4.07)$, followed by chatting $(\mathrm{M}=3.72)$, passing through $(\mathrm{M}=3.67)$, watching other people $(\mathrm{M}=3.65)$ and meeting someone $(M=3.60)$. Again, eating and drinking activities remain to be the most sought activities due to the presence of food stalls at MBI Terrace.

The distributions of activities in the square during the daytime were observed to be scattered. At night, the patterns of activities are more active at MBI Terrace, which is where the food stalls are (Figure 4). The visual activeness of the crowds is contributed by the presence of the food stalls that add liveliness to the square at night, when there are no events held. Interestingly, young people are seen to park and display their cars as part of an informal social gathering at the road between the square and Majlis Bandaraya Ipoh's building (Figure 5). This reveals another aspect of how existing crowds draw in more crowds to the square. 
PLANNING MALAYSIA

Journal of the Malaysia Institute of Planners (2017)

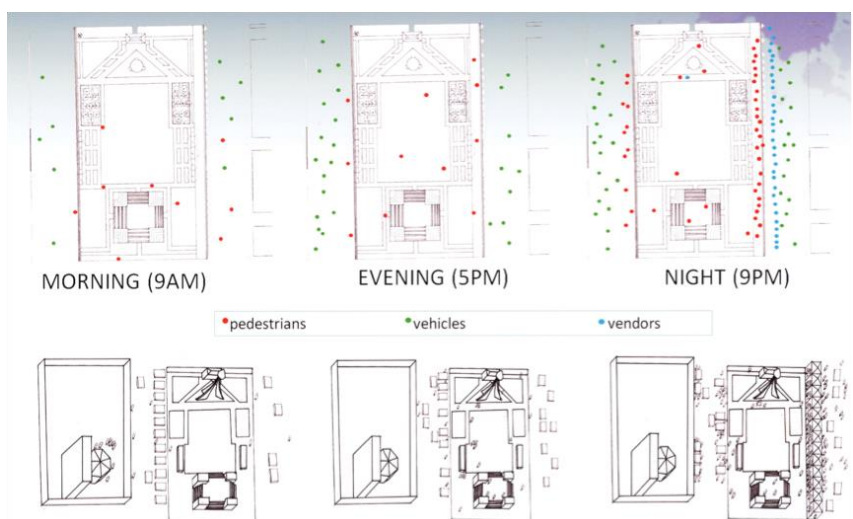

Figure 4 Distribution of Activities at Dataran MBI

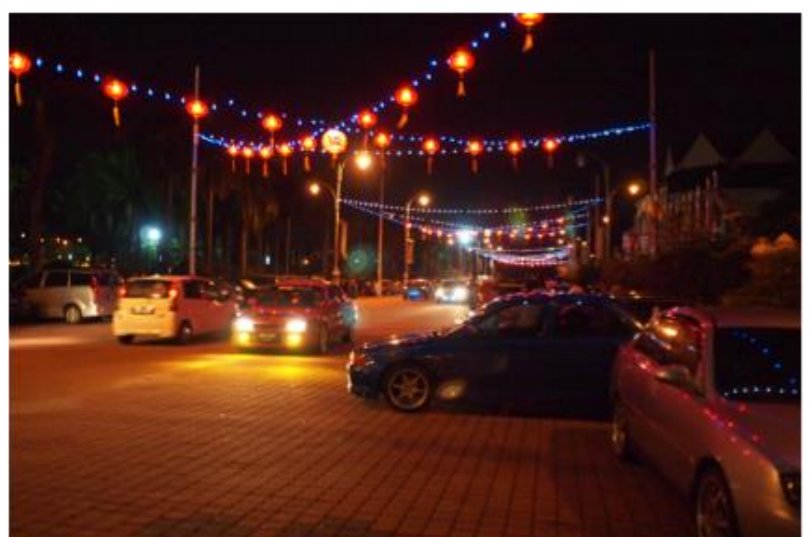

Figure 5 Some Visitors Park and 'Display' Their Cars As They Socialize

\section{Attributes of Dataran MBI}

The square brings several different meanings to the visitors. The survey indicated that Dataran MBI is most recognized as a place for events $(\mathrm{M}=4.11)$ and as a place to socialize $(\mathrm{M}=4.10)$. This is closely followed by visitors perceiving the square as a place for recreation $(M=3.97)$ and a landmark for Ipoh $(M=3.78)$. The square is seen less as a place with historical significance or a place for relaxation. A correlation test is conducted to analyse the relationship between the four meanings of the square towards visitors (see Table 4). There are two significant relationships found to be important from this finding. The square is a place to socialize as it is regarded as a place for recreation $(\mathrm{r}=0.466)$. It is also a place for events with a landmark to Ipoh $(\mathrm{r}=0.384)$. This important relationship indicates that the role of an urban square as a public space is multi-dimensional. To accommodate visitors' socializing activities, the square must be facilitated with 
Khalilah Zakariya, Nor Zalina Harun, \& Mazlina Mansor

Field, Light and Food: Adapting of the Town Square as a Leisure Gathering Space at Night

activities for leisure and recreation. Then to draw crowds for events, it must have some cultural significance to the city, such as a landmark that people can easily identify with the place.

Table 4 Correlations on the Meaning of the Square to Visitors

\begin{tabular}{lll}
\hline & A landmark in Ipoh & A place for recreation \\
\hline A place to socialize & .196 & $\mathbf{. 4 6 6}^{* *}$ \\
A place for events & $\mathbf{. 3 8 4}^{* *}$ & $\mathbf{. 3 6 3}^{* *}$ \\
\hline
\end{tabular}

In terms of accessibility of the square, visitors found the square to be well connected, visible and accessible (Table 5).

Table 5 Accessibility of the Square

\begin{tabular}{ll}
\hline Accessibility & Mean \\
\hline The square is well-connected & 3.46 \\
The square is visible from far & 3.38 \\
The sidewalk is well-connected & 3.25 \\
It is easy to find parking & 3.18 \\
\hline
\end{tabular}

The image is considered to be important towards the visitor's perception of the square (Table 6). Visitors at Dataran MBI prefer the green atmosphere of the square, which makes the square attractive. They felt the square reflects a local image. This is contributed by the presence of the clock tower that has been at the square for more than 20 years.

Table 6 Image of the Square

\begin{tabular}{ll}
\hline Image & Mean \\
\hline Looks green & 3.58 \\
Attractive & 3.28 \\
Reflect local image & 3.22 \\
Clean & 3.15 \\
Well-designed & 3.14 \\
\hline
\end{tabular}

Safety and comfort are other important attributes that influence visitors to come to the square (Table 7). The crowd level at Dataran MBI was found to be tolerable during days without events. The visitors consider the square to be well lit, vibrant with activities and safe. The square is facilitated with a spotlight that lights the open green field, as well as street lighting and decorative lighting around the square (Figure 6). 
PLANNING MALAYSIA

Journal of the Malaysia Institute of Planners (2017)

Table 7 Safety Level of the Square

\begin{tabular}{ll}
\hline Safety & Mean \\
\hline Tolerable crowd & 3.46 \\
Well-lit & 3.43 \\
Vibrant with activities & 3.36 \\
Safe & 3.12 \\
\hline
\end{tabular}

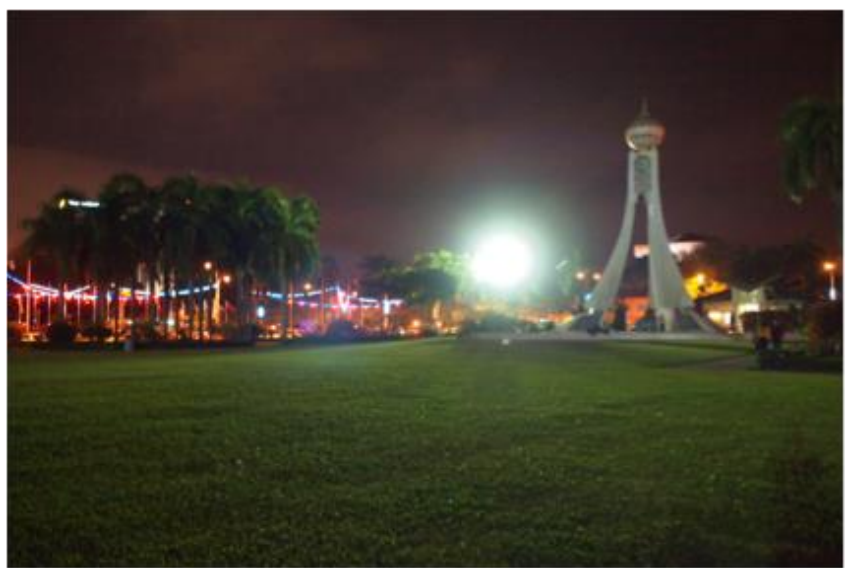

Figure 6 Lighting at the Square

In terms of the provision of facilities at Dataran MBI, visitors prefer that the square offers more retail outlets and food stalls. While they agreed that the square has proper pedestrian walkways, they felt that the square's seating areas, trees and dustbins are less adequate (Table 8). The square green space has the potential to be used for various leisure and recreational activities. However, there are inadequate shady trees and the landscape does not seem to encourage visitors to become attracted to occupy the green space during the day (Figure 7).

Table 8 Satisfaction Level on Facilities at the Square

\begin{tabular}{ll}
\hline Facilities & Mean \\
\hline Retail outlet and food stalls & 3.24 \\
Proper pedestrian walkway & 3.11 \\
Adequate trees & 2.90 \\
Adequate dustbins & 2.78 \\
Well-maintained toilets & 2.56 \\
\hline
\end{tabular}


Khalilah Zakariya, Nor Zalina Harun, \& Mazlina Mansor

Field, Light and Food: Adapting of the Town Square as a Leisure Gathering Space at Night

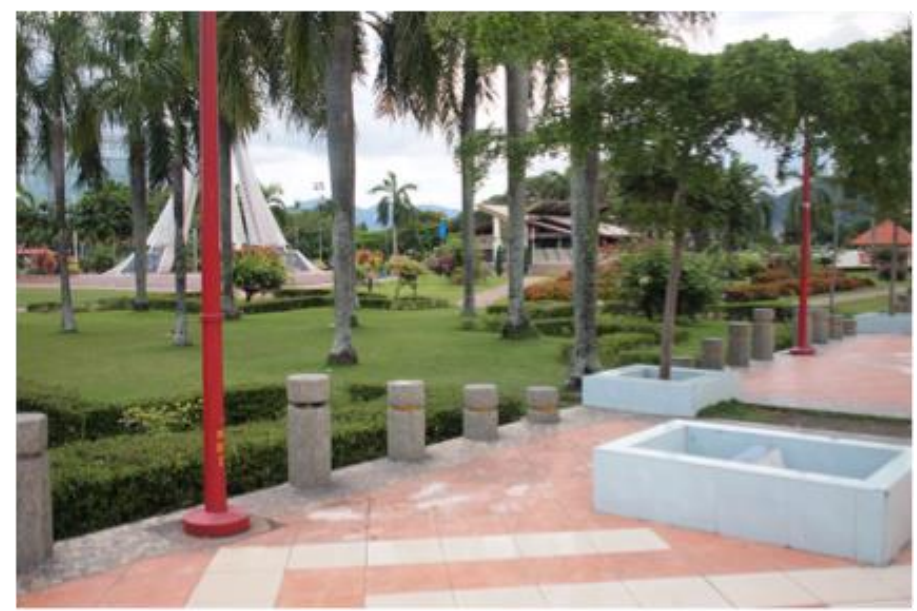

Figure 7 Landscape Design of the Square

\section{Visitors' Suggestions}

There are several suggestions gathered from the respondents on ways to enhance Dataran MBI. The outdoor facilities at the square need to be improved in order to attract more robust activities during the day and night. Similarly the landscape design should offer more trees in some parts of the square to provide shade. In ensuring safety at the square, they suggest for the local authority to increase the patrolling hours. The square also has potential to become a place for educational purposes, where the authorities can generate more ideas for events.

From the survey and suggestions, it can be construed that Dataran MBI is functioning relatively successfully at its scale as a town square. Although Dataran MBI is not as prominent as other squares in Malaysia, such as Dataran Merdeka and Dataran Pahlawan, it is still able to attract daily visitors to the square. Suggestions for improvement can be expected to boost the square's image and role as a vibrant public space and night space gradually in the future.

\section{DISCUSSION AND CONCLUSION}

As revealed in the findings from the questionnaire survey, observation and site mapping, the activeness of Dataran MBI is largely contributed by five key factors:

1. The presence of MBI Terrace food stalls.

2. The events that are held occasionally in the square.

3. The square and the clock tower as landmarks.

4. The location of the square that promotes accessibility (availability of parking, adjacency to a commercial area, surrounded by main roads).

5. The availability of infrastructures (lighting, walkways, open field for activities, areas for vendors, etc.) that attracted people to visit the square in the evening and at night. 
The presence of the food stalls allows visitors to come to the square for 'necessity' activities, which is eating and drinking. Eating in public areas is an activity that strongly relates with socializing. By providing eating areas, the visitors indirectly visit the square and consequently attach their eating activities with the square. However, it is critical to note that simply placing food stalls or food kiosks may not guarantee that people will come. The liveliness of the MBI Terrace food stalls is also significantly contributed by its location next to a commercial area and main roads. This makes the food stalls also 'visually' accessible. The visual activeness that comes from the activities, movements, sounds and lighting at the food stall add liveliness the square, which otherwise would remain less active.

Events are another key activities that are able to attract local and out of town visitors. Since the urban square is one of the open public spaces in a city, its spatial characteristics and openness are usually able to accommodate large crowds compared to parks. The success of an event at an urban square is largely contributed by the location of the square, where accessibility and supporting facility play a major role. In addition, the planning and management of the event by the organizer and the local authority also determine the success of the events. Nonetheless, events are one of the ways of how urban squares can be made active and 'marketed' from time to time. This also may build a stronger image of the square over the years.

Accessibility, infrastructure and adjacencies are equally crucial in encouraging the utilization of an urban square by the public. Parking spaces, wellmaintained public toilets, well connected walkways, robust spaces and lighting are some of the design requirements that need to meet the varieties of users' activities, from children, youths, families to elderlies. For Dataran MBI, the local authority has demarcated the MBI Terrace for temporary food stall vendors. Although the infrastructure provided might be minimal (marking of stall lots for vendors, improving the drainage, providing water taps and widening the sidewalk), this gesture was able to enliven the square on weekday nights. Again, regular and continuous use of the square will eventually enhance the attachment and relationships that people have with it. This is a vital component in building the place attachment among the locals and visitors to the place.

Another interesting attribute that the square has is people's association with it as a landmark. While the MBI Terrace is relatively new, the clock tower and the open field of Dataran MBI have existed as part of Greentown for over 20 years. This signifies a kind of 'soft' infrastructure where there is already a cultural familiarity between people and the square. Since Dataran MBI has already regarded as a landmark, it is much easier for people to recognize and accept the square as part of a public space in Ipoh. 
Khalilah Zakariya, Nor Zalina Harun, \& Mazlina Mansor

Field, Light and Food: Adapting of the Town Square as a Leisure Gathering Space at Night

The adaptation of Dataran MBI into a night public space is important in guiding the design of a good setting for civic and commercial buildings in cities. A place like this is visually, socially and physically accessible as it is believed that its placement, facilities of its surrounding areas also have influenced people's frequent visit. This can simultaneously establish a harmonious relationship amongst the community and visitors. In conclusion, the findings from this pilot study reveals several important key points and attributes that will further be tested at other squares in the country that is currently facing decline in terms of its vibrancy as a public space. Lessons from this study can also help the planning or redevelopment of other town and city squares in Malaysia.

\section{REFERENCES}

Carmona, M., Heath, T., Oc, T., \& Tiesdell, S. (2003). Public places urban spaces: the dimensions of urban design. Oxford: Architectural Press.

Childs, M. C. (2004). Squares: a public place design guide for urbanists. Albuquerque: University of New Mexico Press.

Cooper-Marcus, C., \& Francis, C. (1998). People Places: Design Guidelines for Urban Open Space. New York: John Wiley \& Sons.

Denscombe, M. (2007). The good research guide: for small-scale social research projects. Maidenhead: McGraw-Hill.

Francis, M. (2003). Urban open spaces. Washington, D.C.: Island Press.

International Making Cities Livable. (2002). The European Square. Retrieved from http://www.livablecities.org/articles/european-square-conference-report.

Khalilah Zakariya, \& Nor Zalina Harun (2013). The people's dataran: celebrating historic square as a potential temporary market space. Procedia - Social and Behavioral Sciences, 85, 592-601.

Kostof, S. (1992). The city shaped: urban patterns and meanings through history. London: Routledge.

Lynch, K. (1960). The image of the city. Cambridge: MIT Press.

Lynch, K. (1981). The good city form. Cambridge: The MIT Press.

Nor Zalina Harun, \& Ismail Said (2008). Morphology of padang: a case study of Dataran Merdeka, Kuala Lumpur. In International Seminar in Sustainable Environment \& Architecture. Shah Alam.

Nur Azlini Abdullah (2004). Plaza in Urban Area. International Islamic University Malaysia.

Tibbalds, F. (1992). Making People-Friendly Towns. London: Longman.

Whyte, W. H. (1980). The social life of small urban spaces. Washington D.C.: The Conservation Foundation.

Yin, R. K. (2003). Case study research: design and methods (3rd ed.). California: Sage.

Zaidah Zainal. (2007). Case study as a research method. Jurnal Kemanusiaan, 9.

Zeisel, J. (1984). Inquiry by design: tools for environment behavior research. New York: Cambridge University Press. 